\title{
Library Consortia in China
}

\author{
Elaine Xiaofen Dong \\ Special Formats Cataloging Librarian, University of Arkansas Libraries \\ Fayetteville, Arkansas \\ Email: edong@uark.edu
}

Tim Jiping Zou

Head of Access Services, Associate Librarian, University of Arkansas Libraries

Fayetteville, Arkansas

Email: tzou@uark.edu

\begin{abstract}
This paper traces the history and development of library consortia in China from 1980 to the present. It also gives examples and descriptions of various types of library consortia in China, including academic, public, special, multi-type library consortia at the regional and national level.

Keywords: Library Consortia, Library Resource Sharing, China

\section{Introduction}

A library consortium is an association of libraries established by formal agreement, usually for the purpose of improving services through resource sharing among its members. In China, a library consortium might take such a name as "alliance," "network," "system,” or "association.”

During the past three decades, the ideas and practice of library cooperation have been progressively affirmed in China. The library consortium, a major form of library cooperation in China, fulfills the common needs of a group of libraries in the areas of collections, staff and user training, services like interlibrary loan, and processes like cooperative acquisitions and cataloging. The intent of this paper is to provide an outline of the history and development of library consortia in China from 1980 to the present as gleaned from selected websites and representative reports in the published literature.
\end{abstract}

\section{History}

Library consortia in China emerged in the 1980s from the need to strengthen cooperation among libraries. Initial efforts were limited to the sharing of collection information via printed bibliographies or catalog cards. Cooperation was later extended to the areas of interlibrary lending and cooperative cataloging in small scale, and occasionally to coordinated acquisitions.

Large-scale cooperation among Chinese libraries was achieved in the 1990s to address resource sharing issues, which have gained momentum largely due to such factors as the prevalence of the Internet and information technology, the exponential growth of publications, and the increasing cost of information resources. However, library consortia mushroomed mostly in economically developed metropolitan areas, and remained marginal in rural and remote areas. Typical consortia during the 1990s were single-type collaborative groups among academic libraries within the same 
geographical region. Most of them were formed to share resources in the areas of acquisitions, cataloging, reciprocal borrowing, and interlibrary lending. Some ventured further to explore ways of building union catalogs, purchasing electronic databases, training staff, delivering documents online, and constructing digital databases. Towards the mid-1990s, many consortia began to create local special digital databases.

The surge of consortia has facilitated the growth of interlibrary loan (ILL) services. ILL services in the past concentrated mostly on the delivering of print documents. Requested information was photocopied, mailed, emailed, or faxed to the requesting library. Borrowing and lending physical items was very limited. Interlibrary borrowing of monographs was limited to reciprocal borrowing agreements under which users of a reciprocal library can go to other member libraries to browse, copy, and check out materials with a unified IC card. Towards the end of the 1990s, some national consortia began to construct national union catalogs and to promote nationwide cooperative cataloging programs. The rise of national union catalogs consequently encouraged greater interest in ILL services among consortial libraries. In 1999, 122 libraries signed the first National Interlibrary Loan Code at a major resource sharing conference hosted by the National Library of China in Beijing.

Cross-regional consortia and national consortia began to gain popularity after 2000 as the scope of resource sharing activities was quickly expanding. Those transregional collaborations were largely enabled by the fast growing national information network infrastructure and spurred by a number of government initiatives for building information network to support educational and economic development. One of the overriding ideas that drove all resource sharing activities, noted by Zhu (2003), is that "no single library can collect all the information [materials] published in the world, and no single library can serve all the needs required by users" (p. 400). Therefore, forming library consortia becomes a strategic move to achieve efficiency and cost effectiveness in developing a national information network in China. Since 2000, more library consortia have been formed in a variety of formats in China. The following sections review the characteristics of these library consortia.

\section{Consortia Today}

Library consortia in China have been formed to fulfill the expectations of their users. Most consortia are identified by: (1) type, such as academic, public, or special library; (2) geographical proximity, and (3) administrative division. In terms of constituting a library consortium, technological feasibility, geographical convenience, and administrative affiliation with the state or a local government are major considerations. Administrative affiliation is the most important factor since most libraries in China are partially or fully supported by the government. The idea of cross-administrative division collaborations became especially appealing after the Internet enabled libraries to be connected via cyberspace. As the forms of library collaboration continue to evolve around emerging information technology, library consortia in China reflect the political and economic reforms that have energized China to steadily move toward modernity.

\section{Regional and Cross-region Consortia}

\subsection{Academic Library Consortia}


Academic libraries were among the earliest to collaborate in China. Academic library consortia emerged in the early 1980s and became prevalent towards the end of the 1990s when many academic libraries were exploring ways to improve efficiency and to resolve constraints on financial resources.

Most of these consortia are network-enabled collaborating groups. Membership is voluntary, but only formal members are eligible to be elected to serve on the administrative council, which is the governing body. Members share the resources through a unified portal that provides 24/7 access to its union catalog, databases, and interlibrary loan services. These consortia offer staff training programs, facilitate cooperative acquisitions and cataloging, and coordinate the development of digital projects and virtual reference services.

One example is Beijing Academic Library Consortium which comprises twenty-seven higher education institutions in Beijing. Its major objectives are: (1) group purchasing of valuable Chinese and foreign databases; (2) cooperatively constructing local special digital databases; (3) enhancing ILL and documentary delivery services; and (4) conducting staff training. The cooperation among members has been enhanced largely by the launch of the consortium's portal in 2001 (Net Library of Beijing High Education, 2008). It integrates all the web-based resources and electronic services provided by member libraries, including union catalogs, digital databases and a virtual reference system.

Another example is Tianjin Academic Library Consortium. A unified portal was developed in 2004 to integrate and distribute web-based information resources of the Consortium members. It consists of a union catalog, e-books, databases and other digital information. Fifteen local special digital databases have been constructed cooperatively by members (Tianjin Academic Library Information System, 2008).

Other examples of academic consortia at regional level include Hebei Academic Digital Library, Guangdong Academic Library Network, and Hubei Academic Library Committee.

\subsection{Public Library Consortia}

Cooperation among public libraries in China is usually limited within a geographical region and has developed unevenly in different geographical areas. Public library consortia have grown and flourished in developed areas such as Beijing, Shanghai, Tianjin, Guangdong and Fujian Provinces, but rarely exist in remote areas such as west regions and the majority of countryside areas. A major objective of public library consortia is still cooperative cataloging and acquisitions because of the present lack of a national comprehensive union catalog.

An example of this type of consortium is Shenzhen Acquisitions and Cataloging Center established in 1993. It comprises all the public libraries in Shenzhen, and it has provided centralized acquisitions, cataloging, and processing of materials for all the members. Later in 2000, cooperative acquisitions and cataloging among members were realized based on a union cataloging system, ILAS, designed by the Shenzhen Public Library. ILAS won many national awards and one international award because of its flexibility, powerful functionality and networking capability. It has been applied in about 2,000 libraries in China (ILAS, 2008). 
Cross-region public library consortia have emerged since 2000. One example is the China Regional Libraries Network (CRLNet, 2008), co-founded in June 2000 by six key public libraries located in six regions. Its major objective is coordinating acquisitions and cataloging of local materials among public libraries in these regions. The priority for each member is to collect and catalog locally published materials as soon as possible so that the bibliographic information can be shared to avoid duplicate work. Incentives are built to encourage sharing. A library is credited 2 RMB (Chinese currency) for each record uploaded, and charged 0.3 RMB for each record exported. The (718) 260-5484consortium has also provided staff training programs for members to standardize process and ensure data quality. CRLNet has been growing and expanding rapidly. At present it has more than seventy members, and about 2 million bibliographic records are now available in its online union catalog.

Some other examples of public library consortia are Guangdong Province Public Library Automation Network and Hubei Public Library Consortium.

\subsection{Multi-Type Library Consortia}

Multi-type consortia are usually formed in a geographical area with the purpose of integrating and sharing information resources of all types of libraries in the area.

One example is the Shanghai Information Resources Network (SIRN, 2008). Established in 1994, SIRN currently has thirty-one members consisting of public, academic, and special libraries in Shanghai. Members have cooperated in collection development, ILL, computer networks, and digital database construction. SIRN has a union cataloging system and an ILL system that allows members to request document delivery services for patrons from other members for a fee. Patrons can use a unified IC card at any library in Shanghai and borrow their materials. In 2003, the consortium signed an agreement with OCLC to share access to more than 1,000 e-books from NetLibrary.

Another example is the Zhejiang Province Digital Resource Network. Co-founded by Zhejiang Public Library, Zhejiang University Libraries, and Zhejiang Science and Technology Institution, the consortium aims to coordinate the purchase of e-resources, cooperatively create local special digital databases, and establish a unified portal to organize, preserve, and disseminate web-based resources in the province (Zhejiang Province Digital Resource Network, 2008).

A unique phenomenon in China is that one single library has multiple functions and acts as the physical and virtual complex for a combination of academic and special libraries. In Shenzhen, for example, a "college town" was built in the outskirt area to attract prestigious universities and research institutions to set up satellite campuses in the area for the purpose of offering degreed programs in demand and further boosting local education and economy. Currently, it hosts five universities' satellite campuses, including Beijing University and Qinghua University. As it is fiscally impossible and a waste of resources for each institute to build a library of its own, the Shenzhen government allocated funds to build a state-of-the-art library to serve all the institutions on the shared campus. It also functions as the new home of Shenzhen Science and Technology Library. The library is the first dual-type library in China and epitomizes resource sharing on multiple levels (Shenzhen University Town Library, 2008).

\section{National Library Consortia}


National library consortia began to emerge at the end of the 1990s, and have had profound effects on national information resource sharing. With unified open interfaces to integrate web-based resources of members nationwide through networks, these consortia have realized the benefits of one-stop information resource retrieval.

\subsection{Academic Library Consortia}

\subsubsection{China Academic Library \& Information System (CALIS, 2008)}

CALIS is a national academic library consortium established in May 1998. It aims to promote and improve resource sharing among academic libraries, reduce the expenses for participating libraries, and support the development of higher education in China. Its long-term goal is to build the largest academic digital library in China, and to construct, integrate, preserve, and distribute digital resources to all the universities and colleges in China. It currently has over 600 members distributed in twenty-seven provinces, cities, and autonomous regions in China.

CALIS has a unique financial support structure. The Central Government invested 60 million RMB initially; each province or city that has a regional center and each member library provides at least same amount of money to match the government's support. In order to sustain its viability, CALIS is moving towards an independent and self-supporting system by seeking funds from external sources and implementing membership and service fees.

CALIS has a national administrative center and four divisions. Services are provided to members through a three-tier information support structure. The first tier includes four national centers that provide information at a national level. The second tier includes twenty-eight regional/provincial centers that oversee and provide services to the third-tier member libraries. Each second-tier member also coordinates resource sharing activities with national centers and other regional/provincial centers, and functions as a "hub" to negotiate, customize and deliver services.

CALIS' Union Cataloging System is the largest and first multi-language cooperative online cataloging system in China. Yao and Chen (2005) asserted that from 2001, the System has had a steady and consistent increase in its membership at a rate of about 100 libraries each year (p. 474). CALIS' ILL system allows members to borrow and lend materials, and deliver scanned documents in a cost effective way. Forty-six members are authorized as service libraries to provide ILL services to other members. ILL services have been increasing rapidly.

CALIS has organized group purchasing of foreign databases for libraries and institutions to reduce costs. By the end of April 2005, CALIS had facilitated sixty-two group purchasing activities which involved more than 790 academic libraries and institutions in China, resulting in the purchase of 216 foreign databases (Yao and Chen, 2005, p. 473). CALIS has also put great efforts into sponsoring and coordinating the creation of local special digital collections. The newly launched CALIS Digital Resource Portal integrates about 260 foreign and Chinese digital resources, including abstract and index databases, e-books, OPACs, newspapers, dissertations, ejournals, and search engines. It allows users to search resources by title, language and subject. The portal is currently on trial and more digital resources will be added to the system in the future (CALIS Digital Resource Portal, 2008).

The CALIS Digital Library Research Center, established in 2003, has investigated and implemented crucial technology and application systems employed in digital library systems, and designed a standardized digital library model to be customized and used by members. The model comprises a unified search platform, a processing system, an ILL system, a virtual reference 
system, and a digital copyright management system. Thus far, twenty-two digital library test sites are under construction.

\subsubsection{China Academic Social Sciences and Humanities Library (CASHL, 2008)}

The mission of CASHL, which was constituted in March 2003, is to cooperatively acquire, preserve and share foreign and Chinese periodical resources in the humanities and social sciences among member libraries, and to provide a unified online portal for users to retrieve and utilize these resources. CASHL is affiliated with CALIS which provides data processing standard and technical support to CASHL.

CASHL also has a three-tier structure comprising member libraries as well as national and regional information centers. Currently it has over eighty member libraries, including academic libraries and libraries in the Chinese Academy of Sciences and Social Sciences System. Thus far there are over 2,800 foreign and Chinese periodicals represented on its website. It adopts centralized document delivery mode: when a user requests a document through the System, CASHL retrieves it from digital databases and member libraries and sends the e-file or scanned file to the user by email.

\subsection{Public Library Consortia}

The National Library of China (NLC, 2008), the largest library in China and the fifth largest in world, is the general repository for all national publications. It plays a leading role in the public library system and has participated in many cooperative projects. For example, it has led cooperative cataloging endeavors of more than 800 public libraries, distributed the MARC records of the National Bibliography to other libraries, and delivered international ILL services through mail and e-mail to over 500 libraries in sixty-three countries. NLC has also been a pioneer in acquiring, creating, preserving and distributing digital contents in China and has established a rich collection of e-resources. NLC has initiated and played a vital role in the following two national consortia.

\subsubsection{Consortium of National Information Resource Sharing}

NLC acts as the national convener and liaison for the consortium to facilitate resource sharing among public libraries at the national, provincial and local levels. Major goals of the consortium include: (1) establishing resource sharing systems; (2) promoting union cataloging and ILL services; (3) cooperatively constructing digital databases; (4) establishing national and regional information reference networks; and (5) strengthening communication and conducting training (Consortium, 2008).

\subsubsection{National Cultural Resources Project (NCRP, 2008)}

The NCRP, launched in April 2002, is a cooperative project supported by the Central Government. It was created mainly by NLC and other public libraries. Its major objectives include:

- Building a national network to create, preserve, and integrate the digital content of Chinese cultural information resources, and provide online access of these valuable resources to the general public in the country 
- Creating a national union catalog for all the cultural information resources of public libraries, museums, art galleries and other art institutions

- Constructing digital databases by digitizing valuable cultural performances and materials, such as local theatre performances, movies, cultural lectures, artwork, and artifacts

Thus far, NCRP has connected 8,187 library centers and stations that cover the majority of public libraries in China, including NLC as the national center, thirty-three provincial centers, and 8,153 local libraries and stations. The types and numbers of digital cultural resources created and made available on NCRP's website are listed in the following table.

\begin{tabular}{|l|c|c|}
\hline & Digital Resources Created & Expected Number by 2010 \\
\hline Local Theatre Performances & 2,190 & 5,500 \\
\hline Agricultural Videos & 2,450 & 7,000 \\
\hline Chinese Movies & 200 & 500 \\
\hline eBooks & 350,000 & $2,100,000$ \\
\hline Cultural Lectures & 586 & 2,586 \\
\hline Texts & 4.6 billion & 15 billion \\
\hline Pictures & 50,000 & 250,000 \\
\hline Multimedia Databases & 42 & About 50 \\
\hline
\end{tabular}

\subsection{Special Library Consortia}

\subsubsection{Medical Library Association of Chinese Universities and College}

Established in 1985, the primary aim of the Association is to build a national medical information sharing network and coordinate the acquisitions of foreign biomedical journals among 151 members. Members consist mainly of academic medical libraries and a few hospital libraries. The cooperative products of members include the Union List Database of Foreign Biomedical Journals in China and the Union List Database of Chinese Biomedical Journals (Medical Library Association, 2008).

\subsubsection{National Science and Technology Library (NSTL, 2008)}

As a national special library consortium, NSTL was established in 2000 and funded by the Central Government. Members comprise eight major national science and technology research institutions, covering the fields of science and technology, engineering, agriculture, and medicine. It aims to collect, organize, and preserve cooperatively and comprehensively science and technology information resources, and extend access to these resources through a unified portal.

As of September 9, 2008, the NSTL union catalog contains about 58 million bibliographic records reflecting the collections of member libraries, among which 29 percent are in Chinese, 19 percent are in Japanese and Russian, and 52 percent are in English and other western languages. Member libraries have been cooperatively purchased books, journals, conference proceedings and other print and electronic materials to avoid duplication. They have also cataloged materials 
cooperatively through a union cataloging system. In terms of document delivery service, once a user submits a request online, the library holding the item will handle and deliver it. NSTL promises to fulfill a regular request in two working days, or will fill an urgent request in one working day.

\section{Conclusion}

During the past three decades, both the construction of a national information highway system and a robust economic growth have facilitated the cooperation among Chinese libraries on a large scale. The availability of several major national information networks has provided a direct impetus for libraries to be connected through the networks and to explore models of digital libraries. In a global economic environment, building a resourceful and efficient national information system becomes strategically imperative for China to sustain its economic growth and to develop a world-class education system.

Library consortia in China were first developed around large cities and provinces along the coasts where economies are booming and higher education institutions are concentrated. In these areas, capital investments and human resources are abundant. Library consortia go hand in hand with the consolidation and integration of government agencies and state-owned businesses, especially after China became a member of World Trade Organization in order to remain relevant and competitive. Most consortia, therefore, are formed along the library type based on the restructured financial and administrative divisions and sectors. During the last ten years, more cross-region, cross-sector, multi-type library consortia have emerged to address regional education and economic needs. Library resource sharing in the rural and remote areas still lags behind due to lack of funding and technological support. However, recently there have been activities to extend services to these areas.

Thus far, most library consortia in China have focused on sharing resources in the areas of cooperative acquisitions and cataloging, reciprocal borrowing services, interlibrary borrowing and online document delivery, centralized staff training, and technological development. At the national level, building a national digital library has become a top priority as in the cases of CALIS, CASHL, NCIRSP, and NSTL. These consortia have quickly and effectively expanded access to a world of digital resources, have made available more foreign databases nationally through group licensing and purchasing, and have delivered the information to end users through a pay-per-use method. In recent years, some large consortia have also stepped up international collaboration efforts. A few large library consortia have joined OCLC and established reciprocal programs with large library systems in other countries.

The regional, cross-region, and national consortia introduced in this paper represent the major developments and achievements in China's quest for modernization of its national information infrastructure. These library consortia have played significant roles in setting the direction and shaping the national trends in information resource sharing in the country. 


\section{Acknowledgements}

The authors would like to thank Anne Marie Candido from the Dean's Office of the University of Arkansas Libraries, for her valuable editorial advice.

\section{References}

CALIS (China Academic Library \& Information System). (2008). Retrieved September 9, 2008 from http://www.calis.edu.cn

CALIS Digital Resource Portal. (2008). Retrieved September 9, 2008 from http://metasearch.lib.pku.edu.cn/uss/uspportal/ResSelectIP.aspx

CASHL (China Academic Social Sciences and Humanities Library). (2008). Retrieved September 9, 2008 from http://www.cashl.edu.cn

Consortium of National Information Resource Sharing. (2008). Retrieved September 9, 2008 from http://www.nlc.gov.cn/old/old/newpages/english/cooperate/index.htm

CRLNet (China Regional Libraries Network). (2008). Retrieved September 9, 2008 from http://www.crlnet.org

ILAS. (2008). Retrieved September 9, 2008 from http://www.ilas.com.cn

Medical Library Association of Chinese Universities and Colleges. (2008). Retrieved September 9, 2008 from http://168.160.60.100/xiehui/jianjie.htm

NCRP (National Cultural Resources Project). (2008). Retrieved September 9, 2008 from

http://www.ndcnc.gov.cn

Net Library of Beijing High Education. (2008). Retrieved September 9, 2008 from

http://www.netlib.edu.cn

NLC (National Library of China). (2008). Retrieved September 9, 2008 from

http://www.nlc.gov.cn/en/indexen.htm

NSTL (National Science and Technology Library). (2008). Retrieved September 9, 2008 from http://www.nstl.gov.cn/index.html

Shenzhen University Town Library. (2008). Retrieved September 9, 2008 from http://lib.utsz.edu.cn/news/2007-03-22/24_1174899012109.shtml

SIRN (Shanghai Information Resources Network). (2008). Retrieved September 9, 2008 from http://www.libnet.sh.cn/newsirn/english/indexen.htm 
Tianjin Academic Library Information System. (2008). Retrieved September 9, 2008 from http://www.tjdl.cn/index.jsp

Yao, X. X., Chen, L. (2005). Exploring the services provided by CALIS: meeting the needs of member libraries. Library Management, 26(8/9), 471-477

Zhejiang Province Digital Resource Network. (2008). Retrieved September 9, 2008 from http://www.zjdh.org

Zhu, Q. (2003). China Academic Library and Information System: Current Situation and Future Development. International Information \& Library Review, 35(2/4), 399-405.

$\operatorname{Pg} 10$

LIBRES ISSN 1058-6768 Volume 19, Issue 1, March 2009 